\title{
Optimum of Dual Antiplatelet Duration and Followed Monotherapy in Diabetes Mellitus After Percutaneous Coronary Intervention With Drug- Eluting Stent Implantation: A Bayesian Network Meta-Analysis of 20536 Patients From 18 Randomized Trials
}

Ke An

Medical School of Southeast University,Nanjing; Department of Endocrinology, Affiliated Zhongda Hospital of Southeast University, No.87 DingJiaQiao Road, Nanjing

Peng Guo

Changlu Street Community Health Service Center, No.68 BaiYu Road, Nanjing

Shanhu Qiu

Medical School of Southeast University, Nanjing; Department of Endocrinology, Affiliated Zhongda Hospital of Southeast University, No.87 DingJiaQiao Road, Nanjing

\section{Wenwen Zhu}

Southeast University Medical School Affiliated Nanjing Chest Hospital: Nanjing Chest Hospital

\section{Wuyou Cao}

Southeast University Medical School Affiliated Nanjing Chest Hospital: Nanjing Chest Hospital Jijing Shi

Southeast University Medical School Affiliated Nanjing Chest Hospital: Nanjing Chest Hospital Shaohua Wang ( gyjwsh@126.com )

Affiliated ZhongDa Hospital of Southeast University https://orcid.org/0000-0001-9567-6668

Original investigation

Keywords: Diabetes Mellitus, Dual Antiplatelet Therapy, Network Meta-analysis, Percutaneous Coronary Intervention, Drug-Eluting Stent

Posted Date: January 28th, 2021

DOl: https://doi.org/10.21203/rs.3.rs-154514/v1

License: (9) This work is licensed under a Creative Commons Attribution 4.0 International License.

Read Full License 
Page 2/24 


\section{Abstract}

Background: To evaluate the efficacy and safety of short-term ( $\leq 3$-month) dual antiplatelet therapy (DAPT), midterm (6-month) DAPT, standard-term (12-month) DAPT and extended-term (『12-month) DAPT in diabetes after percutaneous coronary intervention (PCl) with drug-eluting stent (DES). To Compare discontinuation of DAPT followed by aspirin with P2Y12 inhibitor monotherapy for detailed optimal scheme.

Methods: Randomized, controlled trials were searched using PubMed, Web of Science, Embase, Cochrane library and clinicaltrials.gov. up to October 10, 2020. A Bayesian network meta-analysis was conducted with a random-effect model.

Results: A total of 18 randomized trials encompassing 20536 diabetic patients were included. Network analysis showed that short-term DAPT is best for reducing primary endpoint, which is superior to extended-term DAPT (odds ratio $0.48,95 \% \mathrm{Cl} 0.25$ to 0.85 ). Standard-term was also associated with reduce risk of primary endpoint in comparison with prolonged DAPT $(0.56,0.32$ to 0.90$)$. There was no noticeable difference with respect to primary endpoint between short-term DAPT followed by aspirin monotherapy and P2Y12 inhibitor monotherapy. No significant differences were observed in secondary endpoints, including all-cause mortality, cardiac mortality, MI, stroke, TVR, definite or probable stent thrombosis and major bleeding.

Conclusions: Short-term DAPT was associated with the better primary endpoint benefit for patients with diabetes after PCI with DES, compared with extended-term DAPT. Although the optimal duration should balance risk-benefit ratio between personal ischemic and bleeding events, this study suggested short term DAPT followed by P2Y12 inhibitor monotherapy may be the optimal therapy for most diabetes after PCI with DES.

\section{Background}

Diabetes mellitus (DM) patients are a well-known high-risk group of severe coronary artery disease (CAD), and the incidence of postoperative adverse clinical events is higher than that of general population[1, 2]. Dual antiplatelet therapy (DAPT), aspirin and a P2Y12 inhibitor, is the cornerstone to prevent the stent thrombosis and reduce ischemic events after percutaneous coronary intervention (PCl) with drug-eluting stent (DES) implantation[3, 4]. As the contradiction between ischemia benefits and hemorrhagic risks of DAPT, the optimal duration is pivotal factor to strike a balance for patients to benefit ultimately[5]. Due to impaired glucose metabolism, usage of hypoglycemic and hypolipemic drugs, such as statins which share the same cytochrome P450 isoenzyme 3A4 (CYP3A4) pathway with clopidogrel, and glucose fluctuation, the standard 6-12-month DAPT following DES implantation that current clinical practice guidelines recommend for general population may not be suitable for the diabetes in particular[6].

Furthermore, debates that whether prolong or abbreviate the DAPT treatment still exist[7, 8]. Multiple randomized clinical trials (RCTs) and observational studies have explored the fit time with contradictory 
conclusions among diabetes[9, 10,11]. Previous meta-analysis qualitatively showed that there is no significantly difference between extended and short term DAPT therapy in ameliorating adverse clinical outcomes among subjects with diabetes mellitus, except ascending bleeding in prolonged DAPT use[12, 13]. Yet the evidence appraising the role of diabetes in the choice of the optimal time remains limited.

In addition, despite the safety and efficacy of discontinuing aspirin in favor of P2Y12 inhibitor monotherapy remains ambiguous, there are currently no head-to-head RCTs comparing discontinuation of DAPT followed by aspirin or P2Y12 inhibitor monotherapy[14]. Further network analysis compared among diabetes could be conducted to shed a light from indirect comparison.

Therefore, we performed this network meta-analysis (NMA) on a variety of DAPT duration strategies to probe the favorable duration and discontinuation of DAPT followed appropriate monotherapy which is applicable for diabetic population for clinical guidance and subsequent studies.

\section{Methods}

\section{Search strategy and data sources}

An electronic search was conducted systematically for literature published up to October 10, 2020. The database comprised PubMed, Embase, Web of Science, clinicaltrials.gov. and Cochrane Library, and references of related articles were also searched to ensure the integrity of the data as far as possible. The following search terms were made of use: "dual antiplatelet", "drug-eluting stent", "percutaneous coronary intervention" and "randomized controlled trial". The detailed search strategy was provided in Additional file 1.

\section{Inclusion and exclusion criteria}

Screening of retrieved articles was carried out on the basis of the predefined inclusion criteria below: (1) studies were clinical RCTs; (2) participants were adults with DM who received DAPT after PCI after DES;

(3) the therapies were candidate durations of DAPT, like short term ( $\leq 6$ months), standard term (12 months) and extended term ( $₫ 12$ months); (4) outcomes were reported such as primary endpoint, allcause mortality, cardiac mortality, myocardial infarction (MI), stroke, target vessel revascularization (TVR), stent thrombosis and bleeding events; (5) at least 12-month follow-up.

Studies that met the following criteria were excluded: (1) they were pharmacokinetic and pharmacodynamic studies, meta-analyses, observational research, case studies or editorials; (2) patients involved were not DM; (3) they did not set adverse outcome events as their clinical endpoints; (4)they were involved the identical or reduplicate trials.

\section{Data extraction and quality evaluation}

Two independent investigators (KA and PG) assessed the studies involved, adjudicated data and reviewed the methodological quality of each eligible trial. Any disagreement occurred during the data 
extraction process, the opinion of a third researcher (SHW) was sought to make a final decision. Information concerning trial names, year of publication, sample size, treatment and control group, outcomes, clinical events reported in diabetes group, follow-up period. The bias risk among the trials and the methodological quality of the included studies was assessed by Risk of Bias 2 according to the Cochrane Collaboration's tool [15], which contains preliminary considerations, signaling questions and 5 domains plus overall risk of bias: bias arising from the randomization process, bias due to deviations from intended interventions, bias due to missing outcome data, bias in measurement of the outcome, bias in selection of the reported result and plus 'Overall risk of bias'. Items were scored as low risk, some concerns, or high risk of bias.

\section{Statistical analysis}

We performed Bayesian NMA conducted a random effects model, using the Markov chain Monte Carlo (MCMC) methods. The Gemtc package was run in R to call the JAGS software to achieve the Bayesian NMA. The effect was expressed by odds ratio (OR) and $95 \%$ confidence interval $(\mathrm{Cl})$ to summary statistics to quantify the effects of different duration. Based on non-informative uniform and normal prior distributions [16], the initial values were set for four different chains, 100,000 interactions with 50,000 burn-in samples were produced to obtain the model parameters from the posterior distributions, and 1 thinning rates were adopted for each chain. Convergence was assessed using the trace plots and BrooksGelman-Rubin method to check if the error was $₫ 5 \%$ of the standard deviation of the effect estimates and between-study variance[17]. The estimates of Bayesian NMA were reported as rank probabilities to identify the relative rankings of DAPT duration based on the surface under the cumulative ranking curve (SUCRA), ranging from $0 \%$ (statistically certain to be the worst treatment) to $100 \%$ (statistically certain to be the best treatment) $[18,19,20]$.

Result heterogeneity was examined with Cochrane's Q statistic and quantified with inconsistency statistic $\left(I^{2}\right)$, which was considered as low, moderate, or high for $l^{2}$ values under $25 \%$, between $25 \%$ and $50 \%$, and over $50 \%$, respectively[21]. $P$ less than 0.05 was considered as statistical significance.

Inconsistency was conducted by Gemtc package in R, comparing the deviance residuals and deviance information criterion (DIC) statistics in fitted consistency and inconsistency models to identify any loops in the treatment network where inconsistency was existed[22]. The node splitting approach was also used to assess the inconsistency of the model, in which direct and indirect evidence was separately contrasted on a particular comparison. All statistical analyses were performed using R 3.6.3 (R Foundation for Statistical Computing, Vienna, Austria) and Stata 14.2 (Stata Corporation, College Station, TX, USA).

\section{Outcomes variables}

Outcomes consisted of primary endpoint and secondary outcomes. We incorporated definitions of the primary endpoint as applied in each trial. The secondary outcomes were the individual components of the primary outcome, containing mortality, cardiac mortality, MI, stroke, TVR, definite or probable stent 
thrombosis and major bleeding. Stent thrombosis was defined according to criteria from the academic research consortium[23]. The other outcomes were defined differently in Additional file 2.

\section{Results}

\section{Study search and study characteristic}

Of 3506 articles, 652 were screened after duplicates were deleted, 2830 were excluded by reviewing the title and abstract level, and additional 6 related studies were removed for unpublished data, observational trial or cannot be grouped[24, 25, 26, 27, 28, 29] (Figure 1). Eighteen trials were ultimately included with a total of 20536 diabetic patients randomly assigned to receive one of the following four kinds of DAPT durations: short-term ( $\leq 3$-month), midterm (6-month), standard-term (12-month), extended-term ( $\$ 12$ month)[10, 11, 30, 31, 32, 33, 34, 35, 36, 37, 38, 39, 40, 41, 42, 43, 44, 45]. Besides, short-term DAPT followed by aspirin monotherapy in comparison with P2Y12 monotherapy was conducted for further study. The characteristics of included RCTs for the NMA are shown in Table 1. Detailed inclusion and exclusion criteria of trials are represented in Additional file 3.

\section{Quality of evidence}

The detailed risk of bias assessments was summarized in Figure 2. The overall heterogeneity assessment of the results showed that the heterogeneity was low for cardiac mortality $\left(1^{2}=0 \%\right)$, stroke $\left(I^{2}=0 \%\right)$, TVR $\left(I^{2}=6.27 \%\right)$ and major bleeding $\left(I^{2}=0 \%\right)$. However, moderate to high heterogeneity was detected in comparisons of the primary endpoint $\left(I^{2}=28.75 \%\right)$, all-cause mortality $\left(I^{2}=28.19 \%\right), \mathrm{MI}\left(I^{2}=\right.$ $25.51 \%$ ), stent thrombosis (definite or probable) $\left(I^{2}=64.76 \%\right.$ ) observation indicators, although the $95 \% \mathrm{Cls}$ showed that this heterogeneity was not statistically significant. Forest plots of feasible pairwise comparisons with heterogeneity estimates were generated in Additional file 4.

The fit of the consistency model was similar to or better than that of the inconsistency model (Additional file 5). Inconsistency between direct and indirect estimates from the node splitting analysis did not show significant differences in each comparison (Additional file 6). The convergence diagnosis model can be used to predict the data effectively. We evaluated the convergence of iterations by visual inspection of the chains to establish homogenous parameter estimates and to comply with the Brooks - Gelman - Rubin diagnostic standard (Additional file 7).

\section{Network meta-analysis}

\section{Efficacy and safety}

Network plots for different outcomes were generated to illustrate the geometries, to clarify which treatments were compared directly or indirectly in the included studies[46]. The network evidence plot of primary endpoint and was shown in Figure 3, while that of short-term DAPT followed by P2Y12 inhibitor or aspirin monotherapy and secondary outcomes was shown in Additional file 8. All of contribution plot was also demonstrated in Additional file 8. Moreover, the primary endpoint result of NMA using random- 
effects were summarized in Table 2. Other NMA clinical events result were demonstrated in Additional file 9.

\section{Primary endpoint}

Compared with extended-term DAPT, short-term DAPT and standard-term DAPT was associated with a reduced risk of primary endpoint (OR $0.48,0.25$ to $0.85 ; 0.56,0.32$ to 0.9 ), whereas midterm DAPT showed no significant difference (OR $0.62,0.33$ to 1.06 ). Furthermore, short-term DAPT followed by P2Y12 inhibitor or aspirin monotherapy had no remarkable difference compared to short-term DAPT followed by aspirin monotherapy (OR $0.90,0.54$ to 1.5 ). According to the accumulative rankings by SUCRA, we found that the possible best treatment improving primary endpoint was 3-month DAPT, while the effect is consistent with midterm and standard term DAPT. In addition, in the analyses of the primary endpoint, the worst treatment was extended-term DAPT.

\section{Secondary outcomes}

All-cause mortality was similar in extended-term DAPT, 12-month DAPT, mid-term DAPT or short-term DAPT. No noticeable difference was also shown for cardiac mortality. Compared with 12-month DAPT, extended-term DAPT, mid-term DAPT and short-term DAPT showed no significant differences in the matter of Ml or in respect of stroke. In terms of definite or probable stent thrombosis, compared with 12month DAPT, extended-term DAPT, mid-term DAPT and short-term DAPT showed no significant differences. Similar result was also shown on the subject of TVR. There were no significant differences with respect to major bleeding between the different DAPT strategies.

\section{Rank probabilities}

Figures 4 and Figure 5 show the ranking probabilities for all treatments included (with detail ranking results for other outcomes summarized in Additional file 10 and 11). For the treatment effect of ameliorating primary endpoint, short-term DAPT and standard-term DAPT ranked first with the highest probability $(72.18 \%$ and $63.55 \%$, respectively), while midterm and extended-term DAPT ranked last with the highest probability (62.84\% and $95.32 \%$, respectively). For the effect of reducing all-cause mortality, midterm DAPT ranked first with the highest probability (37.59\%), while the extended-term DAPT had the highest probability of ranking last in the incidence of more all-cause mortality (53.43\%). The short-term DAPT had the highest probability of ranking first in the incidence of less cardiac mortality and $\mathrm{Ml}(42.98 \%$ and $64.05 \%$ ), while the midterm DAPT had the highest probability of ranking last in the incidence of more cardiac mortality and $\mathrm{MI}$ ( $52.57 \%$ and $54.27 \%$, respectively). According to the analysis of stroke and TVR, midterm DAPT (76.61\%) and standard-term (44.92\%) were the treatments with the highest probability of achieving a good prognosis. In contrast, the treatments with the lowest probability were short-term and midterm DAPT, with a probability of $46.15 \%$ and $43.52 \%$, respectively. For the effect of delaying the progression of definite or probable stent thrombosis, short-term DAPT was the most appropriate treatment strategy for ranking first with the highest probability $(52.67 \%)$, while midterm ranked last with 
the highest probability (81.18\%). To postpone the event of major bleeding, midterm DAPT was favorable treatment for diabetes (59.08\%), while extend-term DAPT achieved the worst outcome (89.32\%).

\section{Discussion}

In this NMA, which included 18 randomized trials covering 20536 patients, we comprehensively summarized and analyzed the comparative efficacy and safety of various duration of DAPT among diabetes patients after PCI with DES. The results showed that short-term DAPT had the highest cumulative probability of ranking first in the effect of improving primary endpoint. The analysis of primary endpoint data showed that short-term and standard-term DAPT was significantly superior to extend-term DAPT. In addition, short-term DAPT followed by P2Y12 inhibitor monotherapy had a potential advantage over short-term DAPT followed by aspirin monotherapy. There was no obvious statistical difference for secondary outcomes among most treatments. In terms of cardiac mortality, MI, and definite or probable stent thrombosis, short-term DAPT had the greatest probability of ranking first (the lowest cardiac mortality, the lowest MI, and the lowest definite or probable stent thrombosis), and midterm DAPT had the greatest probability of ranking last (the highest cardiac mortality, the highest $\mathrm{MI}$, and the highest definite or probable stent thrombosis). According to the evaluation of all-cause mortality, stroke and major bleeding among diabetes patients, we found that midterm DAPT was the treatments with the highest probability of achieving a good prognosis. In the matter of TVR, the treatments with the highest probability were standard-term DAPT. Our finding provided a clue to understand the prognostic significance of optimal DAPT duration in special diabetic subjects after PCI with DES.

Our current study indicated that short-term DAPT was correlated with better primary endpoint and there was no difference with aspect of stent thrombosis or major bleeding between short-term and extended term DAPT duration, which overturned the traditional idea that diabetes as high-risk population should prolongate DAPT duration for the risk of revascularization and better prognosis.

The finding could be explained in several aspects below. Firstly, it has been shown that statin did not influence the platelet activation and aggregation in patients receiving clopidogrel by our previous metaanalysis[47]. Furthermore, with the refinements in DES technologies and the application of new upgrading DES and even degradable stents, it become possible to shorten the time course of DAPT rather than reduce the risk of thrombosis at the expense of bleeding even in high-risk diabetic patients[48].

A number of recent clinical trials have explored the efficacy and safety of long-term P2Y12 inhibitors monotherapy after short-term DAPT ( $\leq 3$ months) after $\mathrm{PCl}$ among general population, including STOPDAPT-2 (ShorT and OPtimal duration of Dual AntiPlatelet Therapy-2)[49], TWILIGHT (Ticagrelor With Aspirin or Alone in High-Risk Patients After Coronary Intervention)[50], SMART- CHOICE (SMart Angioplasty Research Team: Comparison between P2Y12 Antagonist MonotHerapy and Dual Antiplatelet Therapy in Patients UndergOing Implantation of Coronary Drug-Eluting Stents) [51] etc., which makes people begin to consider the possibility of stopping aspirin when DAPT is converted to monotherapy. The mentioned studies which were based on the comparison of P2Y $\mathbb{Q}$ monotherapy and long-term DAPT 
(12-15 months), did not directly answer the question of which is better between aspirin and P2Y receptor inhibitor when $\mathrm{PCl}$ patients are converted to monotherapy. A recent network meta-analysis which was included 17 RCTs with a total of 54625 patients also confirmed that among general population, there were no significant differences in the incidence of all-cause death, myocardial infarction, stent thrombosis and stroke, or bleeding events between aspirin and P2Y12 inhibitors (clopidogrel) when DAPT was converted to monotherapy in the short-term ( $<6$ months)[52]. Our results which focused on specified diabetes status found the similar result that the efficacy and safety of P2Y12 inhibitors long-term monotherapy was not better than aspirin in aspect of composite primary endpoint.

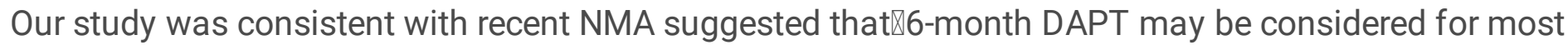
patients after PCI with DES[7], meanwhile the other NMA found the similar result that among general

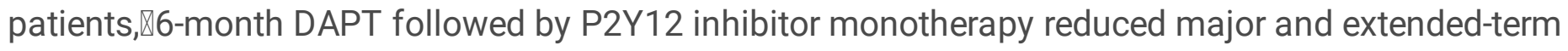
DAPT reduced $\mathrm{Ml}$ at the expense of more bleeding risk[8]. Our result also indicated that even among highrisk diabetic population, short-term DAPT remained be considered first to reduce composite primary endpoint.

Although there have been traditional meta-analysis studies in diabetic population, there is currently no NMA to compare various time courses of DAPT. Our research and finding fill the gap in this area, and provide direction for clinical and future research of diabetic population.

Our NMA is the first to focus on specified diabetes patients, while most studies pay more attention to general population at current time when people performed the RCT or meta-analysis of dual antiplatelet duration and followed monotherapy after PCI with DES. In addition, duration of DAPT was divided into four detailed categories with standard term as control for NMA, and the stratifications can provide more vehicles in understanding the clinical significance of short-term DAPT in diabetes. NMAs often bring out substantially accurate summary results with a combination of direct and indirect comparisons[53].

Of course, there are still some limitations to this study. Firstly, the data source of NMA is based on the collection of published clinical studies, which were consist of inevitable confounding factors in the included data. The heterogeneity indicated by the $\mathrm{I}^{2}$ values among the studies remained, despite the usage of a random-effects model. Although all the included articles in this study are officially published RCTs, the consistency and transmissibility of the data should still be paid attention to in the estimation and interpretation of the results. Secondly, we performed a quantitative NMA based mostly on secondary data, which could lead to inaccurate results for a shortage of original individual patient data. Thirdly, we conducted analysis of some outcomes with pooled definitions. Finally, P2Y12 inhibitors further cannot be further subdivided into clopidogrel, prasugrel, ticagrelor and other new kind of P2Y inhibitors. Further research should differentiate the classification of P2Y12 inhibitor.

\section{Conclusions}


In conclusion, we have found that short-term DAPT was correlated with the better primary endpoint benefit for patients with diabetes after PCI with DES, compared with extended-term DAPT. Although the optimal duration should consider risk-benefit ratio between personal ischemic and bleeding events, this study suggested short term DAPT followed by P2Y12 inhibitor monotherapy may be the optimal therapy for most diabetes after $\mathrm{PCl}$ with DES.

\section{Abbreviations}

\section{DAPT}

dual antiplatelet therapy; PCl:percutaneous coronary intervention; DES:drug-eluting stent; DM:Diabetes mellitus; CAD:coronary artery disease; CYP3A4:cytochrome P450 isoenzyme 3A4; RCT:randomized clinical trial; NMA:network meta-analysis; Ml:myocardial infarction; TVR:target vessel revascularization; MCMC:Markov chain Monte Carlo; OR:odds ratio; Cl:confidence interval; SUCRA:surface under the cumulative ranking curve; DIC:deviance information criterion; STOPDAPT-2:ShorT and OPtimal duration of Dual AntiPlatelet Therapy-2; TWILIGHT:Ticagrelor With Aspirin or Alone in High-Risk Patients After Coronary Intervention; SMART- CHOICE:SMart Angioplasty Research Team:Comparison between P2Y12 Antagonist MonotHerapy and Dual Antiplatelet Therapy in Patients UndergOing Implantation of Coronary Drug-Eluting Stents.

\section{Declarations}

\section{Acknowledgements}

Not applicable.

\section{Authors' contributions}

SHW and KA conceived and designed the research, KA and PG acquired the data, performed statistical analysis. KA drafted, revised and approved the manuscript submitted. SHQ, WWZ, WYC and JJS assisted with the writing of the manuscript. All authors read and approved the final manuscript.

\section{Funding}

This work was partially supported by the National Natural Science Foundation of China (No.81870568, Shaohua Wang).

\section{Availability of data and materials}

Data are available from the authors on request.

\section{Ethics approval and consent to participate}

Not applicable. 


\section{Consent for publication}

Not applicable.

\section{Competing interests}

The authors declare that they have no competing interests.

\section{Author details}

${ }^{1}$ Department of Endocrinology, Affiliated Zhongda Hospital of Southeast University, No.87 DingJiaQiao Road, Nanjing, PR China, 210009. ${ }^{2}$ Medical School of Southeast University, Nanjing, PR China, 210009. ${ }^{3}$ Changlu Street Community Health Service Center, No.68 BaiYu Road, Nanjing, PR China, 211512

\section{References}

1. Beckman JA, Creager MA, Libby P. Diabetes and atherosclerosis: epidemiology, pathophysiology, and management. Jama. 2002 May 15;287(19):2570-81. doi: 10.1001/jama.287.19.2570. PubMed PMID: 12020339; eng.

2. Grant P, Cosentino F, Marx N. Diabetes and coronary artery disease: not just a risk factor. Heart (British Cardiac Society). 2020;106(17):1357-1364. doi: 10.1136/heartjnl-2019-316243. PubMed PMID: 32499237.

3. Valgimigli M, Bueno H, Byrne RA, et al. 2017 ESC focused update on dual antiplatelet therapy in coronary artery disease developed in collaboration with EACTS: The Task Force for dual antiplatelet therapy in coronary artery disease of the European Society of Cardiology (ESC) and of the European Association for Cardio-Thoracic Surgery (EACTS). European heart journal. 2018 Jan 14;39(3):213260. doi: 10.1093/eurheartj/ehx419. PubMed PMID: 28886622; eng.

4. Levine GN, Bates ER, Bittl JA, et al. 2016 ACC/AHA Guideline Focused Update on Duration of Dual Antiplatelet Therapy in Patients With Coronary Artery Disease: A Report of the American College of Cardiology/American Heart Association Task Force on Clinical Practice Guidelines. Journal of the American College of Cardiology. 2016.

5. Miyazaki Y, Suwannasom P, Sotomi Y, et al. Single or dual antiplatelet therapy after PCl. Nature reviews Cardiology. 2017 May;14(5):294-303. doi: 10.1038/nrcardio.2017.12. PubMed PMID: 28181585; eng.

6. Francesco C, Grant PJ, Victor A, et al. 2019 ESC Guidelines on diabetes, pre-diabetes, and cardiovascular diseases developed in collaboration with the EASD. European heart journal. 2019 (2):2.

7. Yin SH, Xu P, Wang B, et al. Duration of dual antiplatelet therapy after percutaneous coronary intervention with drug-eluting stent: systematic review and network meta-analysis. BMJ (Clinical research ed). 2019 Jun 28;365:I2222. doi: 10.1136/bmj.I2222. PubMed PMID: 31253632; PubMed Central PMCID: PMC6595429 at www.icmje.org/coi_disclosure.pdf and declare: support from the 
Major Science and Technology Project of Hunan Province, The National Natural Science Foundation of China, and National Key Research and Development Projects for the submitted work; no financial relationships with any organisations that might have an interest in the submitted work in the previous three years; no other relationships or activities that could appear to have influenced the submitted work.

8. Khan SU, Singh M, Valavoor S, et al. Dual Antiplatelet Therapy After Percutaneous Coronary Intervention and Drug-Eluting Stents: A Systematic Review and Network Meta-Analysis. Circulation. 2020 Oct 13;142(15):1425-1436. doi: 10.1161/CIRCULATIONAHA.120.046308. PubMed PMID: 32795096; PubMed Central PMCID: PMC7547897.

9. Thukkani AK, Agrawal K, Prince L, et al. Long-Term Outcomes in Patients With Diabetes Mellitus Related to Prolonging Clopidogrel More Than 12 Months After Coronary Stenting. Journal of the American College of Cardiology. 2015 Sep 8;66(10):1091-101. doi: 10.1016/j.jacc.2015.06.1339. PubMed PMID: 26337986; PubMed Central PMCID: PMCPmc4578293. eng.

10. Song H PG, Lee CH, Park JS, Ahn JM, Oh JH,et al. Duration of Dual Antiplatelet Therapy after Implantation of Drug-Eluting Stents in Diabetic Patients: A Subgroup Analysis of the Randomized, Clinical Trial. Journal of the American College of Cardiology. 2010;56(13Suppl):B27.

11. Kim BK, Hong MK, Shin DH, et al. A new strategy for discontinuation of dual antiplatelet therapy: the RESET Trial (REal Safety and Efficacy of 3-month dual antiplatelet Therapy following Endeavor zotarolimus-eluting stent implantation). Journal of the American College of Cardiology. 2012 Oct 9;60(15):1340-8. doi: 10.1016/j.jacc.2012.06.043. PubMed PMID: 22999717.

12. Gargiulo G, Feres F, Hong MK, et al. Short- versus long-term dual antiplatelet therapy after drugeluting stent implantation in patients with or without diabetes: a patient-level meta-analysis of randomised trials [Conference Abstract]. European heart journal. 2016;37(suppl 1):1-189. doi: 10.1093/eurheartj/ehw431. English.

13. Lone AN, Khan MU, Khan MZ, et al. Dual antiplatelet therapy after percutaneous coronary intervention with drug-eluting stent in diabetic patients: A meta-analysis of randomized clinical trials [Conference Abstract]. Catheterization and Cardiovascular Interventions. 2020 May 1;95:S37-S38. doi: 10.1002/ccd.28864. PubMed PMID: 32406980; English.

14. O'Donoghue ML, Murphy SA, Sabatine MS. The Safety and Efficacy of Aspirin Discontinuation on a Background of a P2Y12 Inhibitor in Patients After Percutaneous Coronary Intervention: A Systematic Review and Meta-Analysis. Circulation. 2020 Aug 11;142(6):538-545. doi:

10.1161/CIRCULATIONAHA.120.046251. PubMed PMID: 32551860.

15. Higgins JP, Altman DG, Gøtzsche PC, et al. The Cochrane Collaboration's tool for assessing risk of bias in randomised trials. BMJ (Clinical research ed). 2011 Oct 18;343:d5928. doi: 10.1136/bmj.d5928. PubMed PMID: 22008217; PubMed Central PMCID: PMCPMC3196245 www.icmje.org/coi_disclosure.pdf (available on request from the corresponding author) and declare support from the Cochrane Collaboration for the development and evaluation of the tool described; they have no financial relationships with any organisations that might have an interest in the 
submitted work in the previous three years and no other relationships or activities that could appear to have influenced the submitted work. eng.

16. Sutton $\mathrm{A}$, Ades AE, Cooper $\mathrm{N}$, et al. Use of indirect and mixed treatment comparisons for technology assessment. PharmacoEconomics. 2008;26(9):753-67. doi: 10.2165/00019053-200826090-00006. PubMed PMID: 18767896; eng.

17. BROOKS, Stephen P, GELMAN, et al. General methods for monitoring convergence of iterative simulations. Journal of Computational \& Graphical Statistics. 1998.

18. Jansen JP, Fleurence R, Devine B, et al. Interpreting indirect treatment comparisons and network meta-analysis for health-care decision making: report of the ISPOR Task Force on Indirect Treatment Comparisons Good Research Practices: part 1. Value in health : the journal of the International Society for Pharmacoeconomics and Outcomes Research. 2011 Jun;14(4):417-28. doi: 10.1016/j.jval.2011.04.002. PubMed PMID: 21669366.

19. Salanti G, Ades AE, loannidis JP. Graphical methods and numerical summaries for presenting results from multiple-treatment meta-analysis: an overview and tutorial. Journal of clinical epidemiology. 2011 Feb;64(2):163-71. doi: 10.1016/j.jclinepi.2010.03.016. PubMed PMID: 20688472.

20. Tonin FS, Rotta I, Mendes AM, et al. Network meta-analysis: a technique to gather evidence from direct and indirect comparisons. Pharmacy practice. 2017 Jan-Mar;15(1):943. doi:

10.18549/PharmPract.2017.01.943. PubMed PMID: 28503228; PubMed Central PMCID: PMC5386629.

21. Higgins JP, Thompson SG, Deeks JJ, et al. Measuring inconsistency in meta-analyses. BMJ (Clinical research ed). 2003 Sep 6;327(7414):557-60. doi: 10.1136/bmj.327.7414.557. PubMed PMID: 12958120; PubMed Central PMCID: PMC192859.

22. Dias S, Welton NJ, Sutton AJ, et al. NICE DSU Technical Support Document 4: Inconsistency in Networks of Evidence Based on Randomised Controlled Trials. 2014.

23. Cutlip DE, Windecker $S$, Mehran R, et al. Clinical end points in coronary stent trials: a case for standardized definitions. Circulation. 2007 May 1;115(17):2344-51. doi:

10.1161/circulationaha.106.685313. PubMed PMID: 17470709; eng.

24. Kandzari DE, Barker CS, Leon MB, et al. Dual antiplatelet therapy duration and clinical outcomes following treatment with zotarolimus-eluting stents. JACC Cardiovascular interventions. 2011 Oct;4(10):1119-28. doi: 10.1016/j.jcin.2011.06.017. PubMed PMID: 22017938.

25. Valgimigli M, Campo G, Monti M, et al. Short- versus long-term duration of dual-antiplatelet therapy after coronary stenting: a randomized multicenter trial. Circulation. 2012 Apr 24;125(16):2015-26. doi: 10.1161/CIRCULATIONAHA.111.071589. PubMed PMID: 22438530.

26. Bonaca MP, Bhatt DL, Cohen M, et al. Long-Term Use of Ticagrelor in Patients with Prior Myocardial Infarction. New England Journal of Medicine. 2015 May 7;372(19):1791-1800. doi:

10.1056/Nejmoa1500857. PubMed PMID: WOS:000353974700004; English.

27. Hahn JY, Bin Song Y, Oh JH, et al. 6-month versus 12-month or longer dual antiplatelet therapy after percutaneous coronary intervention in patients with acute coronary syndrome (SMART-DATE): a 
randomised, open-label, non-inferiority trial. Lancet (London, England). $2018 \mathrm{Mar}$ 31;391(10127):1274-1284. doi: 10.1016/S0140-6736(18)30493-8. PubMed PMID: WOS:000428791600026; English.

28. Kedhi E, Fabris E, van der Ent M, et al. Six months versus 12 months dual antiplatelet therapy after drug-eluting stent implantation in ST-elevation myocardial infarction (DAPT-STEMI): randomised, multicentre, non-inferiority trial. Bmj-British Medical Journal. 2018 Oct 2;363. doi: Artn K3793 10.1136/Bmj.K3793. PubMed PMID: WOS:000446837900001; English.

29. Krackhardt F, Waliszewski M, Rischner J, et al. Nine-month clinical outcomes in patients with diabetes treated with polymer-free sirolimus-eluting stents and 6-month vs. 12-month dualantiplatelet therapy (DAPT). Herz. 2018;44(9670):1-7.

30. Gwon HC, Hahn JY, Park KW, et al. Six-month versus 12-month dual antiplatelet therapy after implantation of drug-eluting stents: the Efficacy of Xience/Promus Versus Cypher to Reduce Late Loss After Stenting (EXCELLENT) randomized, multicenter study. Circulation. 2012 Jan 24;125(3):505-13. doi: 10.1161/CIRCULATIONAHA.111.059022. PubMed PMID: 22179532.

31. Feres F, Costa R, Bhatt D, et al. Impact of Short- Versus Long-Term Dapt in Patients with Diabetes Mellitus Undergoing Percutaneous Intervention with Endeavor Zotarolimus-Eluting Stents - a Subanalysis of the Large, Prospective, Randomized, Multicenter Optimize Trial. Journal of the American College of Cardiology. 2014 Apr 1;63(12):A1859-A1859. doi: Doi 10.1016/S07351097(14)61862-3. PubMed PMID: WOS:000359579102617; English.

32. Collet JP, Silvain J, Barthelemy O, et al. Dual-antiplatelet treatment beyond 1 year after drug-eluting stent implantation (ARCTIC-Interruption): a randomised trial. Lancet (London, England). 2014 Nov 1;384(9954):1577-1585. doi: 10.1016/S0140-6736(14)60612-7. PubMed PMID: WOS:000343901700026; English.

33. Meredith IT, Tanguay JF, Kereiakes DJ, et al. Diabetes Mellitus and Prevention of Late Myocardial Infarction After Coronary Stenting in the Randomized Dual Antiplatelet Therapy Study. Circulation. 2016 May 3;133(18):1772-+. doi: 10.1161/Circulationaha.115.016783. PubMed PMID: WOS:000375604400007; English.

34. Lee CW, Ahn JM, Park DW, et al. Optimal Duration of Dual Antiplatelet Therapy After Drug-Eluting Stent Implantation: A Randomized, Controlled Trial. Circulation. 2013.

35. Schulz-Schupke S, Byrne RA, ten Berg JM, et al. ISAR-SAFE: a randomized, double-blind, placebocontrolled trial of 6 vs. 12 months of clopidogrel therapy after drug-eluting stenting. European heart journal. 2015 May 21;36(20):1252-1263. doi: 10.1093/eurheartj/ehu523. PubMed PMID: WOS:000356185900015; English.

36. Didier R, Morice MC, Barragan P, et al. 6- Versus 24-Month Dual Antiplatelet Therapy After Implantation of Drug-Eluting Stents in Patients Nonresistant to Aspirin: Final Results of the ITALIC Trial (Is There a Life for DES After Discontinuation of Clopidogrel). JACC Cardiovascular interventions. 2017 Jun 26;10(12):1202-1210. doi: 10.1016/j.jcin.2017.03.049. PubMed PMID: 28641840; eng. 
37. Helft G, Steg PG, Le Feuvre C, et al. Stopping or continuing clopidogrel 12 months after drug-eluting stent placement: the OPTIDUAL randomized trial. European heart journal. 2016 Jan 21;37(4):365-74. doi: 10.1093/eurheartj/ehv481. PubMed PMID: 26364288.

38. Tarantini G, Nai Fovino L, Tellaroli P, et al. Optimal duration of dual antiplatelet therapy after secondgeneration drug-eluting stent implantation in patients with diabetes: The SECURITY (SecondGeneration Drug-Eluting Stent Implantation Followed By Six- Versus Twelve-Month Dual Antiplatelet Therapy)-diabetes substudy. International journal of cardiology. 2016 Mar 15;207:168-76. doi: 10.1016/j.ijcard.2016.01.068. PubMed PMID: 26803236.

39. Han Y, Xu B, Xu K, et al. Six Versus 12 Months of Dual Antiplatelet Therapy After Implantation of Biodegradable Polymer Sirolimus-Eluting Stent: Randomized Substudy of the I-LOVE-IT 2 Trial. Circulation Cardiovascular interventions. 2016 Feb;9(2):e003145. doi:

10.1161/CIRCINTERVENTIONS.115.003145. PubMed PMID: 26858080.

40. Hong SJ, Shin DH, Kim JS, et al. 6-Month Versus 12-Month Dual-Antiplatelet Therapy Following Long Everolimus-Eluting Stent Implantation: The IVUS-XPL Randomized Clinical Trial. JACC Cardiovascular interventions. 2016 Jul 25;9(14):1438-46. doi: 10.1016/j.jcin.2016.04.036. PubMed PMID: 27212028.

41. Vranckx $P$, Valgimigli $M$, Juni $P$, et al. Ticagrelor plus aspirin for 1 month, followed by ticagrelor monotherapy for 23 months vs aspirin plus clopidogrel or ticagrelor for 12 months, followed by aspirin monotherapy for 12 months after implantation of a drug-eluting stent: a multicentre, openlabel, randomised superiority trial. Lancet (London, England). 2018 Sep 15;392(10151):940-949. doi: 10.1016/S0140-6736(18)31858-0. PubMed PMID: WOS:000444475700026; English.

42. Watanabe H, Domei T, Morimoto T, et al. Effect of 1-Month Dual Antiplatelet Therapy Followed by Clopidogrel vs 12-Month Dual Antiplatelet Therapy on Cardiovascular and Bleeding Events in Patients Receiving PCI The STOPDAPT-2 Randomized Clinical Trial. Jama-Journal of the American Medical Association. 2019 Jun 25;321(24):2414-2427. doi: 10.1001/jama.2019.8145. PubMed PMID: WOS:000473009700020; English.

43. Hahn JY, Bin Song Y, Oh JH, et al. Effect of P2Y12 Inhibitor Monotherapy vs Dual Antiplatelet Therapy on Cardiovascular Events in Patients Undergoing Percutaneous Coronary Intervention The SMART-CHOICE Randomized Clinical Trial. Jama-Journal of the American Medical Association. 2019 Jun 25;321(24):2428-2437. doi: 10.1001/jama.2019.8146. PubMed PMID: WOS:000473009700021; English.

44. De Luca G, Damen SA, Camaro C, et al. Final results of the randomised evaluation of short-term dual antiplatelet therapy in patients with acute coronary syndrome treated with a new-generation stent (REDUCE trial). Eurolntervention : journal of EuroPCR in collaboration with the Working Group on Interventional Cardiology of the European Society of Cardiology. 2019 Dec;15(11):E990-+. doi: 10.4244/Eij-D-19-00539. PubMed PMID: WOS:000501563600012; English.

45. Angiolillo DJ, Baber U, Sartori S, et al. Ticagrelor With or Without Aspirin in High-Risk Patients With Diabetes Mellitus Undergoing Percutaneous Coronary Intervention. Journal of the American College 
of Cardiology. 2020 May 19;75(19):2403-2413. doi: 10.1016/j.jacc.2020.03.008. PubMed PMID: 32240760; eng.

46. Chaimani A, Higgins JP, Mavridis D, et al. Graphical tools for network meta-analysis in STATA. PloS one. 2013;8(10):e76654. doi: 10.1371/journal.pone.0076654. PubMed PMID: 24098547; PubMed Central PMCID: PMC3789683.

47. An K, Huang R, Tian S, et al. Statins significantly reduce mortality in patients receiving clopidogrel without affecting platelet activation and aggregation: a systematic review and meta-analysis. Lipids in Health and Disease. 2019;18.

48. Bangalore S, Kumar S, Fusaro M, et al. Short- and long-term outcomes with drug-eluting and baremetal coronary stents: a mixed-treatment comparison analysis of 117762 patient-years of follow-up from randomized trials. Circulation. 2012 Jun 12;125(23):2873-91. doi:

10.1161/circulationaha.112.097014. PubMed PMID: 22586281; eng.

49. Watanabe H, Domei T, Morimoto T, et al. Effect of 1-Month Dual Antiplatelet Therapy Followed by Clopidogrel vs 12-Month Dual Antiplatelet Therapy on Cardiovascular and Bleeding Events in Patients Receiving PCl: The STOPDAPT-2 Randomized Clinical Trial. Jama. 2019 Jun 25;321(24):2414-2427. doi: 10.1001/jama.2019.8145. PubMed PMID: 31237644; PubMed Central PMCID: PMC6593641.

50. Ndrepepa G, Kastrati A, Menichelli M, et al. Ticagrelor or Prasugrel in Patients With Acute Coronary Syndromes and Diabetes6खMellitus. JACC Cardiovascular interventions. 2020 Oct 12;13(19):22382247. doi: 10.1016/j.jcin.2020.07.032. PubMed PMID: 33032712; eng.

51. Hahn JY, Song YB, Oh JH, et al. Effect of P2Y12 Inhibitor Monotherapy vs Dual Antiplatelet Therapy on Cardiovascular Events in Patients Undergoing Percutaneous Coronary Intervention: The SMARTCHOICE Randomized Clinical Trial. Jama. 2019 Jun 25;321(24):2428-2437. doi:

10.1001/jama.2019.8146. PubMed PMID: 31237645; PubMed Central PMCID: PMC6593635.

52. Kuno $T$, Ueyama $H$, Takagi $H$, et al. P2Y12 inhibitor monotherapy versus aspirin monotherapy after short-term dual antiplatelet therapy for percutaneous coronary intervention: Insights from a network meta-analysis of randomized trials. American heart journal. 2020 Sep;227:82-90. doi:

10.1016/j.ahj.2020.06.008. PubMed PMID: 32693196.

53. Riley RD, Jackson D, Salanti G, et al. Multivariate and network meta-analysis of multiple outcomes and multiple treatments: rationale, concepts, and examples. BMJ (Clinical research ed). 2017 Sep 13;358:j3932. doi: 10.1136/bmj.j3932. PubMed PMID: 28903924; PubMed Central PMCID: PMC5596393 interests and declare: none.

\section{Tables}


Table 1

Characteristics of included trials

\begin{tabular}{|c|c|c|c|c|c|}
\hline Trial & Year & $\begin{array}{l}\text { Sample } \\
\text { size }\end{array}$ & $\begin{array}{l}\text { DAPT } \\
\text { groups }\end{array}$ & Endpoints for diabetes & $\begin{array}{l}\text { Mean } \\
\text { follow- } \\
\text { up } \\
\text { (month) }\end{array}$ \\
\hline $\begin{array}{l}\text { REAL/ZEST- } \\
\text { LATE }\end{array}$ & 2010 & 704 & $\begin{array}{l}12- \\
\text { month } \\
\text { v } 36- \\
\text { month }\end{array}$ & $\begin{array}{l}\text { Primary endpoint, death from any cause, MI, } \\
\text { stroke, definite ST, repeat revascularization, } \\
\text { TIMI major bleeding }\end{array}$ & 19.7 \\
\hline RESET & 2012 & 292 & $\begin{array}{l}3- \\
\text { month } \\
\text { v } 12- \\
\text { month }\end{array}$ & $\begin{array}{l}\text { Primary endpoint, death from cardiovascular } \\
\text { cause, MI, TVR, definite or probable ST, } \\
\text { major or minor bleeding }\end{array}$ & 12 \\
\hline EXCELLENT & 2012 & 550 & $\begin{array}{l}\text { 6- } \\
\text { month } \\
\text { v } 12- \\
\text { month }\end{array}$ & $\begin{array}{l}\text { Primary endpoint, total death, cardiac death, } \\
\text { MI, death/Ml, cerebrovascular accident, } \\
\text { target-lesion revascularization, TVR, any } \\
\text { revascularization, ST, any bleeding, TIMI } \\
\text { major bleeding, MACCE }\end{array}$ & 12 \\
\hline OPTIMIZE & 2013 & 1103 & $\begin{array}{l}3- \\
\text { month } \\
\text { v } 12- \\
\text { month }\end{array}$ & Primary endpoint, definite/probable ST & 12 \\
\hline $\begin{array}{l}\text { ARCTIC- } \\
\text { Interruption }\end{array}$ & 2014 & 420 & $\begin{array}{l}12- \\
\text { month } \\
\text { v } 30- \\
\text { month }\end{array}$ & Primary endpoint, & 17 \\
\hline DAPT & 2014 & 3391 & $\begin{array}{l}12- \\
\text { month } \\
\text { v } 30- \\
\text { month }\end{array}$ & $\begin{array}{l}\text { Definite ST, probable ST, cardiac death, } \\
\text { vascular death, non-cardiovascular death, } \\
\text { MI, stroke, BARC type } 2 \text { bleeding, BARC type } \\
3 \text { bleeding, BARC type } 5 \text { bleeding, GUSTO } \\
\text { severe bleeding, GUSTO moderate bleeding, }\end{array}$ & 17 \\
\hline DES LATE & 2014 & 1418 & $\begin{array}{l}\text { 12- } \\
\text { month } \\
\text { v } 36- \\
\text { month }\end{array}$ & Primary endpoint & 36 \\
\hline ISAR-SAFE & 2015 & 979 & $\begin{array}{l}6- \\
\text { month } \\
\text { v } 12- \\
\text { month }\end{array}$ & Primary endpoint & 15 \\
\hline ITALIC & 2015 & 685 & $\begin{array}{l}\text { 6- } \\
\text { month } \\
\text { v } 24- \\
\text { month }\end{array}$ & $\begin{array}{l}\text { Primary endpoint, all-cause death, cardiac } \\
\text { death, MI, TVR, minimal bleeding, minor } \\
\text { bleeding }\end{array}$ & 24 \\
\hline
\end{tabular}

MI: myocardial infarction, ST: stent thrombosis, TVR: target vessel revascularization, TLR: target lesion revascularization 


\begin{tabular}{|c|c|c|c|c|c|}
\hline Trial & Year & $\begin{array}{l}\text { Sample } \\
\text { size }\end{array}$ & $\begin{array}{l}\text { DAPT } \\
\text { groups }\end{array}$ & Endpoints for diabetes & $\begin{array}{l}\text { Mean } \\
\text { follow- } \\
\text { up } \\
\text { (month) }\end{array}$ \\
\hline OPTIDUAL & 2015 & 435 & $\begin{array}{l}12- \\
\text { month } \\
\text { v 48- } \\
\text { month }\end{array}$ & $\begin{array}{l}\text { All-cause mortality, cardiac mortality, MI, } \\
\text { stroke, TVR, definite or probable ST, TIMI } \\
\text { major bleeding }\end{array}$ & 48 \\
\hline SECURITY & 2016 & 429 & $\begin{array}{l}6- \\
\text { month } \\
\text { v } 12- \\
\text { month }\end{array}$ & $\begin{array}{l}\text { Primary endpoint, all-cause mortality, } \\
\text { cardiac mortality, MI, definite or probable ST, } \\
\text { TVR, stroke, type } 3 \text { or } 5 \text { BARC bleeding }\end{array}$ & 24 \\
\hline I-LOVE-IT 2 & 2016 & 414 & $\begin{array}{l}6- \\
\text { month } \\
\text { v } 12- \\
\text { month }\end{array}$ & $\begin{array}{l}\text { Primary endpoint, TLF, cardiac death, MI, } \\
\text { TLR, all-cause death, BARC } 3 \text { or } 5 \text { major } \\
\text { bleeding }\end{array}$ & 12 \\
\hline IVUS-XPL & 2016 & 506 & $\begin{array}{l}6- \\
\text { month } \\
\text { v } 12- \\
\text { month }\end{array}$ & Primary endpoint & 12 \\
\hline $\begin{array}{l}\text { GLOBAL } \\
\text { LEADERS }\end{array}$ & 2018 & 4038 & $\begin{array}{l}1- \\
\text { month } \\
\vee 12- \\
\text { month }\end{array}$ & Primary endpoint, BARC 3 or 5 bleeding & 24 \\
\hline $\begin{array}{l}\text { STOPDAPT- } \\
2\end{array}$ & 2019 & 1159 & $\begin{array}{l}1- \\
\text { month } \\
\text { v } 12- \\
\text { month }\end{array}$ & Primary endpoint & 12 \\
\hline $\begin{array}{l}\text { SMART- } \\
\text { CHOICE }\end{array}$ & 2019 & 1122 & $\begin{array}{l}3- \\
\text { month } \\
\text { v } 12- \\
\text { month }\end{array}$ & Primary endpoint, BARC 2,3 or 5 bleeding & 12 \\
\hline REDUCE & 2019 & 298 & $\begin{array}{l}3- \\
\text { month } \\
\text { v } 12- \\
\text { month }\end{array}$ & Primary endpoint & 24 \\
\hline TWLIGHT & 2020 & 2593 & $\begin{array}{l}3- \\
\text { month } \\
\text { v } 12- \\
\text { month }\end{array}$ & $\begin{array}{l}\text { BARC } 2,3 \text { or } 5 \text { bleeding, BARC } 3 \text { or } 5 \\
\text { bleeding, TIMI major or minor bleeding, } \\
\text { GUSTO moderate or severe bleeding, ISTH } \\
\text { major bleeding, all-cause death, } \\
\text { cardiovascular death, MI, stroke, definite or } \\
\text { probable ST, NACE }\end{array}$ & 15 \\
\hline
\end{tabular}


Table 2

Estimate results according to the network meta-analysis on primary endpoint short-term DAPT

$0.77(0.46,1.32) \quad$ midterm DAPT

$0.85(0.62,1.19) \quad 1.1(0.73,1.66) \quad$ standard-term DAPT

$0.48(0.25,0.85) \quad 0.62(0.33,1.06) \quad 0.56(0.32,0.9) \quad$ extended-term DAPT

Figures

3506 reports identified with PubMed(n=361), Web of Science $(\mathrm{n}=895), \quad$ Embase $(\mathrm{n}=1679), \quad$ Cochrane

Library $(\mathrm{n}=489)$, and ClinicalTrials.gov $(\mathrm{n}=82)$

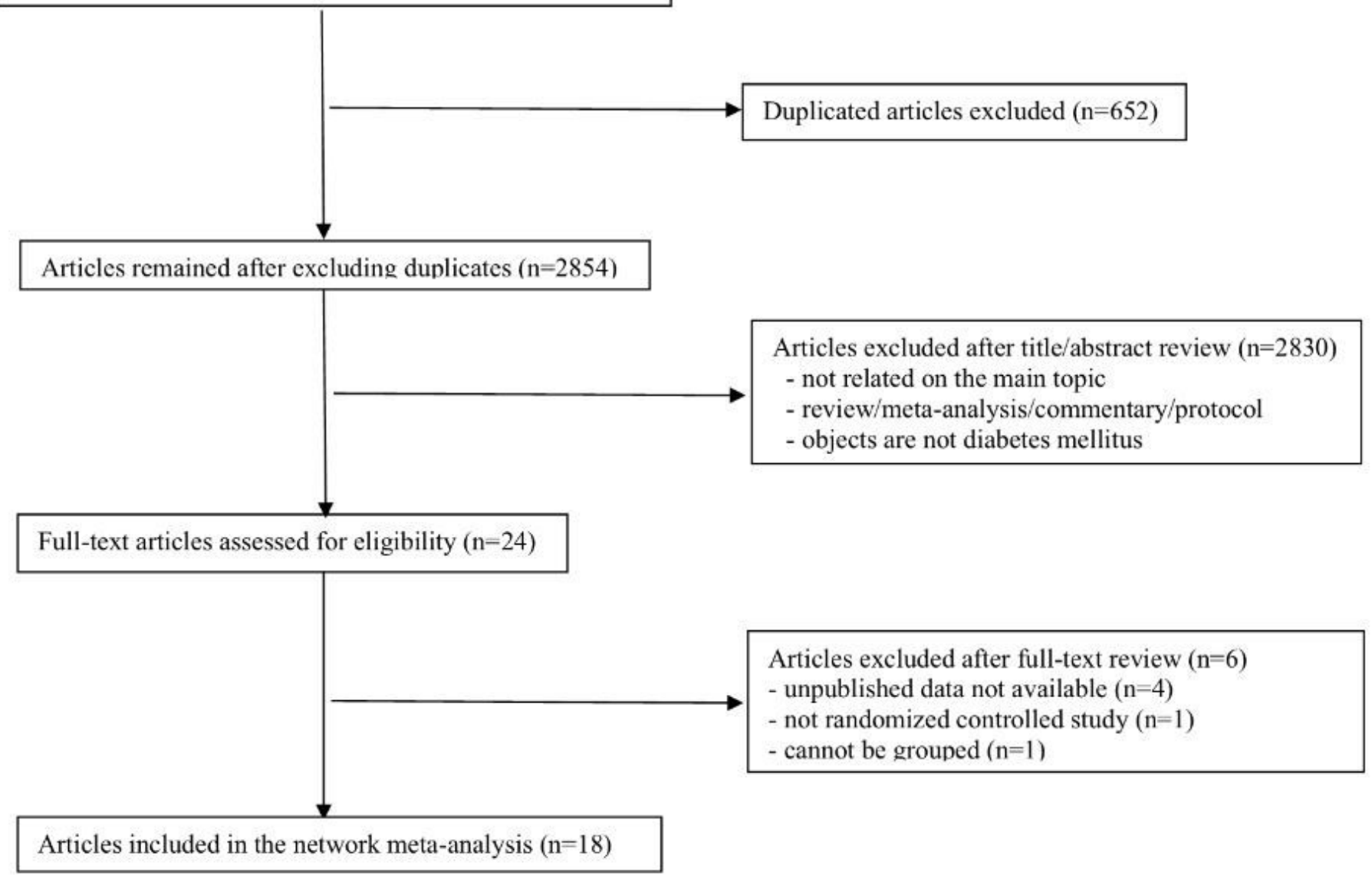

Figure 1

Flow diagram 

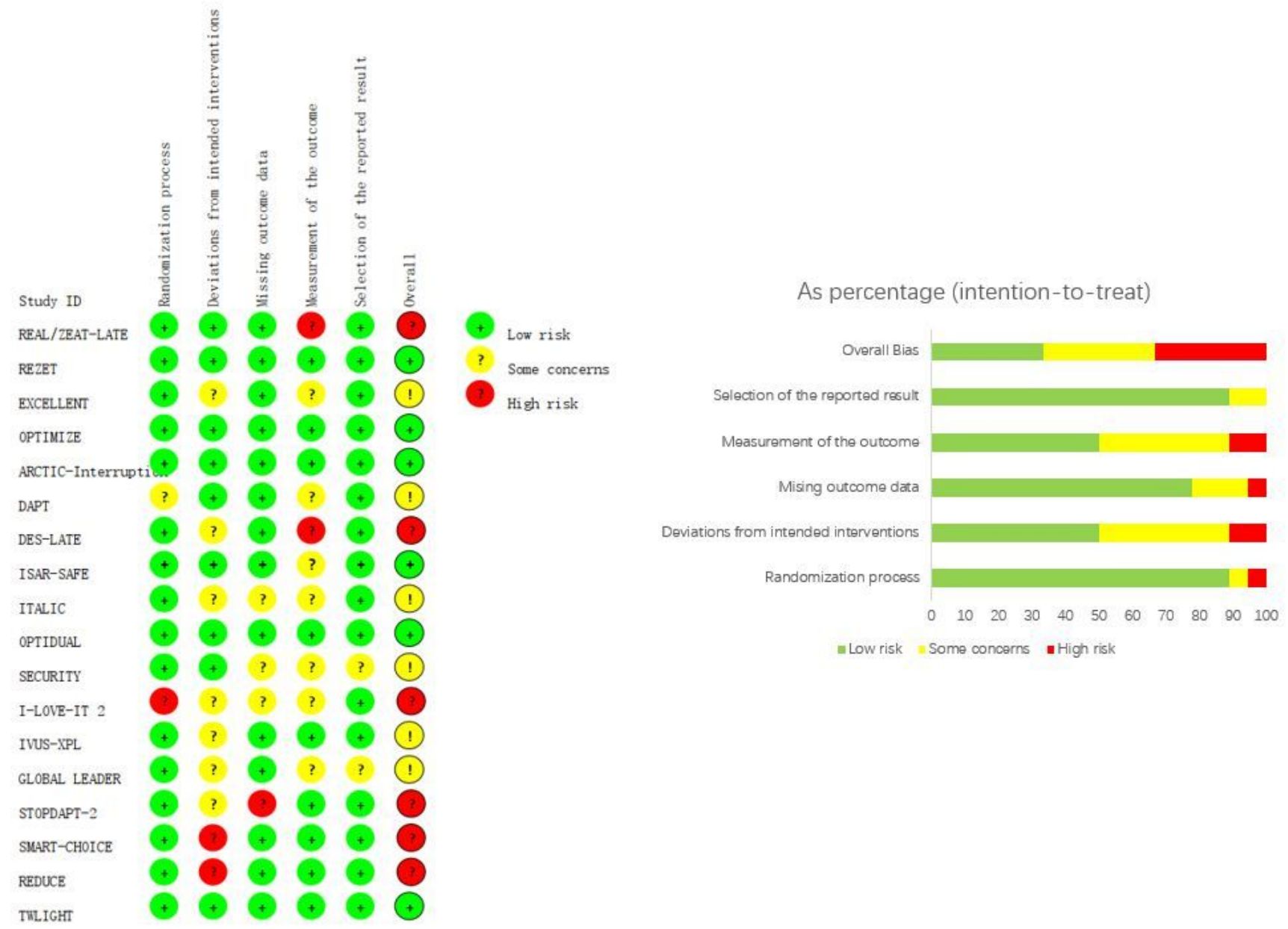

Figure 2

Results from the assessment of the studies 


\section{Network evidence plot for primary endpoint}

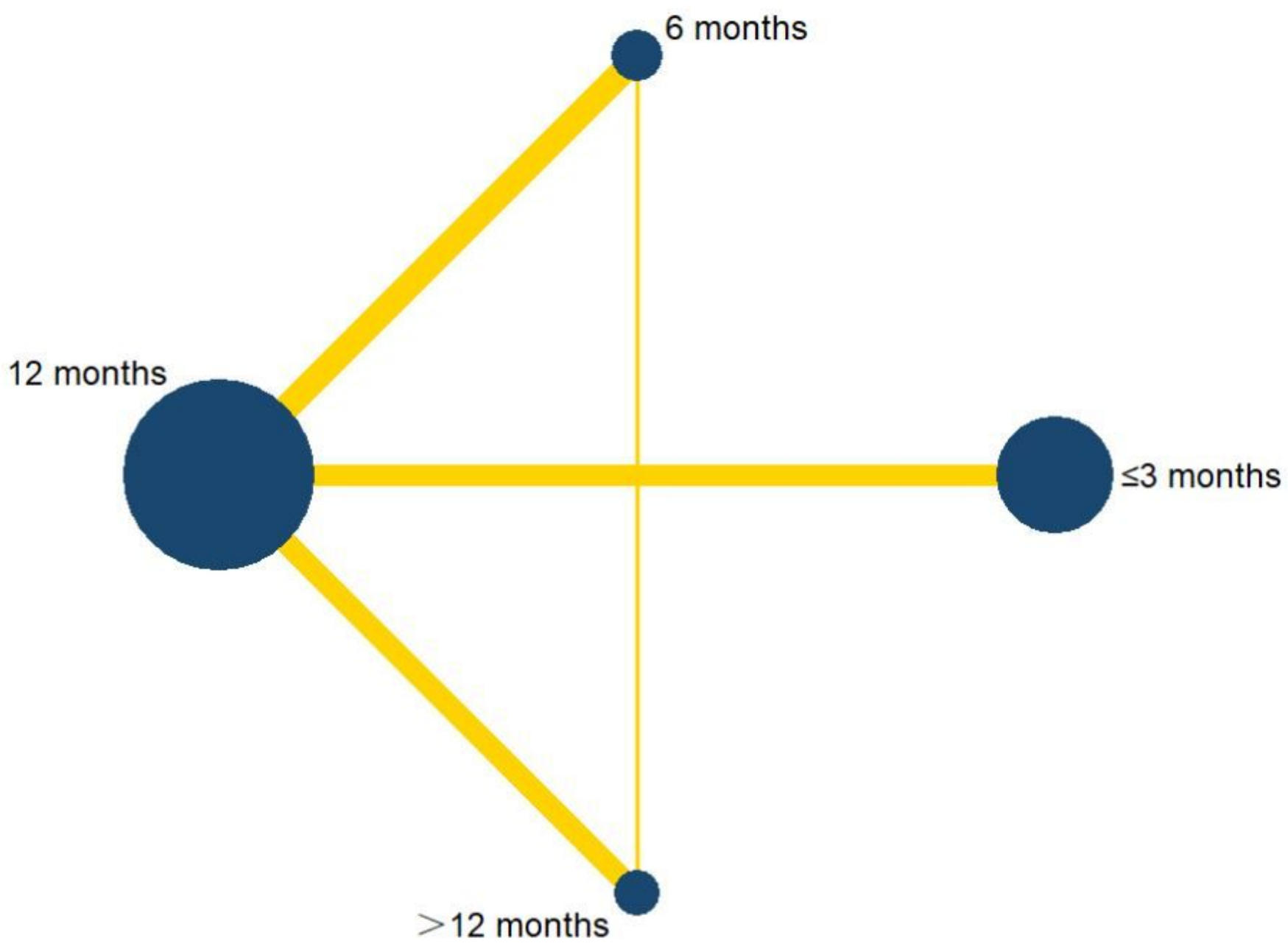

Figure 3

Network evidence plot for primary end point 


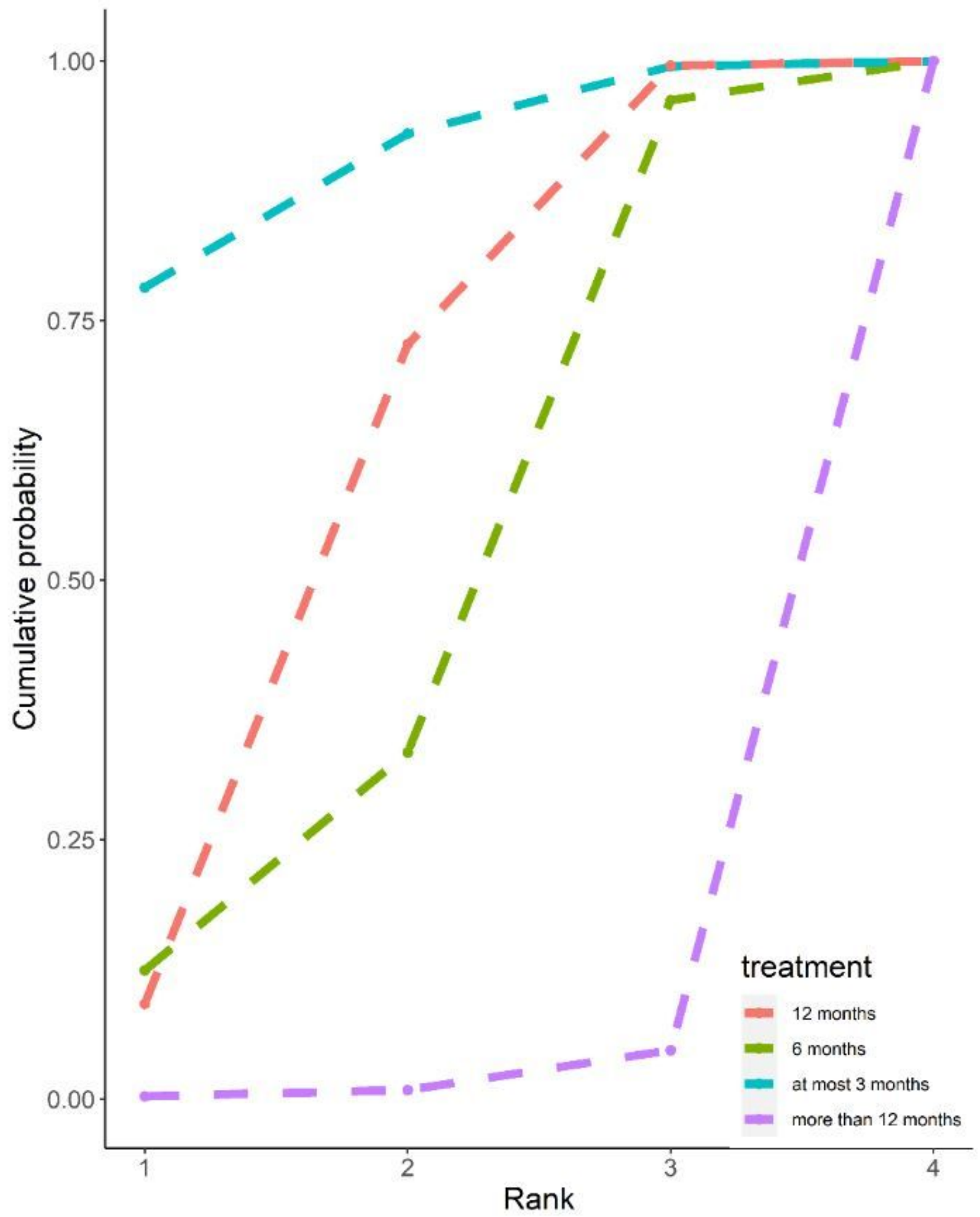

Figure 4

Cumulative ranking curve of primary end point 


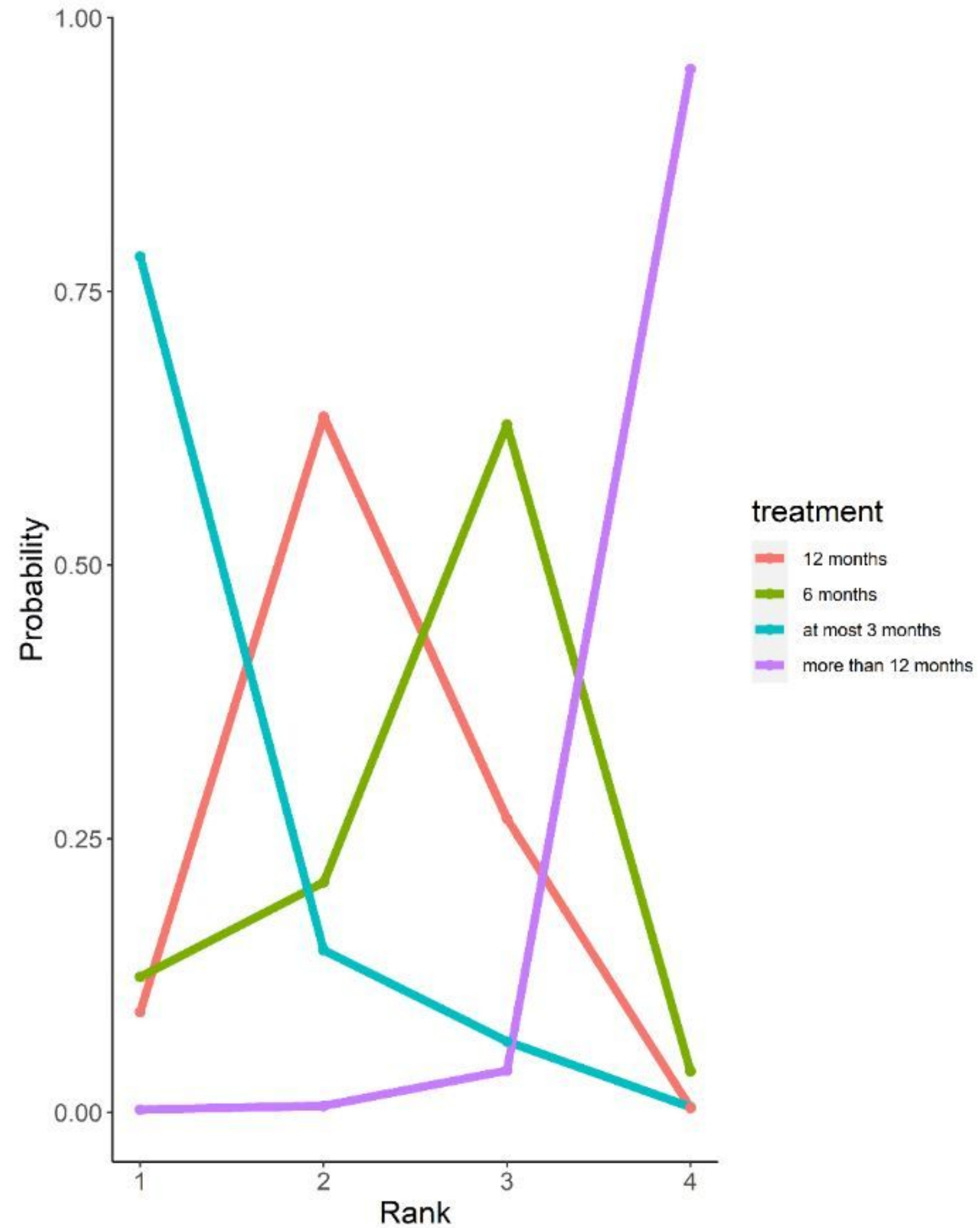

Figure 5

Ranking curve of primary end point

\section{Supplementary Files}

This is a list of supplementary files associated with this preprint. Click to download. 
- Additionalfile1.Searchstrategy.docx

- Additionalfile2.Definition.docx

- Additionalfile3.Inclusionandexclusioncriteria.docx

- Additionalfile4.Forestplots.docx

- Additionalfile5.Consistencyandinconsistency.docx

- Additionalfile6.Nodesplittinganalysisofinconsistency.docx

- Additionalfile7.Theconvergence.docx

- Additionalfile8.Thenetworkplotandcontributionplot.docx

- Additionalfile9.Estimateresultsonclinicalevents.docx

- Additionalfile10.Bayesianrankingresults.docx

- Additionalfile11.Rankingandcumulativerankingcurves.docx 